\title{
Building Knowledge in a Time of Physical Distancing
}

\author{
Douglas McDougall $\mathbb{D}$
}

Published online: 10 June 2020

(C) Ontario Institute for Studies in Education (OISE) 2020

As you begin to read this issue of the Canadian Journal of Science, Mathematics and Technology Education, we hope it can provide a diversion from your current day-to-day life. In recent months, we have all become familiar with concepts like 'physical distancing', 'self-isolation', and 'flattening the curve' - all part of our individual and collective efforts to slow and limit the spread of COVID-19. Collectively, we have done our utmost to protect the health and safety of our community and the wider population. Our hope is that you remain safe and are able to continue to learn about educational issues in this challenging time.

In this issue, we start with a Special Theme on Re-Imagining the M in STEM: Mathematical Actions for Innovative, Resilient and Culturally Rich Communities. The editors for this special theme, Cynthia Nicol, Kathleen Nolan, Florence Glanfield, and Krista Francis, provide an introduction by asking: 'How can the mathematics of STEM and STEM education be reimagined to contribute to more sustainable practices, more innovative, resilient and culturally rich communities?' This Special Theme explores how mathematics education, mathematics teacher education, and STEM education might contribute to our understanding of ecological challenges across national and international contexts.

In the Introduction to the Special Theme, the authors position the papers in the Canada 2067 report (Parkin, 2018), with an emphasis on the need to create opportunities in STEM education to acquire knowledge in cross-cultural understanding, problem solving, and critical thinking. These are key skills for students as they engage in addressing climate change, and other sustainable issues. The articles in this Special Theme provide insights into decolonizing mathematics education (Nicol et al., 2020); authentic mathematical experiences (Leung et al., 2020); mathematics tasks for peace and sustainability (Yaro et al., 2020); multispecies flourishing (Khan, 2020); living landscapes, topographies, architecture, and algorhythms (Glanfield et al., 2020); and teaching and learning emerging from and computing to community (Wiseman et al., 2020).

There are two commentary papers: one from Yasmine Abtahi of the Western Norway University of Applied Sciences and the other by Michael Marker and Shirley Anne Hardman of the University of British Columbia. Abtahi (2020) examines the ways in which mathematics has been instrumental in establishing certain knowledge and ways of being. She further describes how mathematics has been part of the

D. McDougall $(\bowtie)$

Ontario Institute for Studies in Education, University of Toronto, 252 Bloor Street West, Toronto, Ontario M5S 1V6, Canada e-mail: doug.mcdougall@utoronto.ca 
perpetuating dominancy of these knowledges. She describes the challenges in not valuing specific social groups. She provides elements of hope and growth that she sees in the Special Theme papers and beyond.

Marker and Hardman (2020) pose a few questions: What should be counted? How do we do the calculations? What is mathematics and where does it come from? Who are mathematicians and where do they come from? Can we use mathematics to expose the hidden curriculum and hegemonies of settler colonialism? Hardman tells a story about math teachers, place, and the Indigenous community reality from her perspective as an administrator at a university responsible for Indigenous affairs. Marker and Hardman propose the crux of Indigenizing math teaching where 'We want to reflect and include Indigenous learners while at the same time open the minds and the hearts of all students to respecting place, history and ways of knowing of Indigenous peoples' (p. 13).

In addition to the Special Theme, there are five other articles in this issue. Hanin and Van Nieuwenhoven (2020) explore the cognitive, motivational, emotional, and regulatory behaviours of elementary school children problem solvers. She conducted a study to investigate the verbal and written output of above-average and belowaverage problem solvers. She noted that the 'above-average' problem solvers took full responsibility of the external demand by demonstrating a thorough understanding of the problem through the construction of a model. These problem solvers implement control strategies and set up regulatory processes when an error is detected. Above-average problems solvers have positive self-efficacy beliefs and use functional emotional and motivational regulation strategies. On the other hand, some below-average problem solvers have a low level of confidence in their ability and there is a trend that general levels of self-efficacy may be higher than expected at the beginning of schooling but begins to drop as students move to secondary school. This article delves into many aspects of above- and below-average problems solvers as they engage in mathematical tasks.

Bowen and Stelmach (2020) studied the parents of children who participated in science fairs. The parents described their role in supporting their children, how they understood science, and how they perceived the science fair experience on their children. Through three cases, the authors describe the assistance that parents give to their students in science fair projects including technical support and hiring graphic designers. Bowen and Stelmach wonder about the extent to which high parent participation in a science project reflects the community cultural capital of the students and not the work of the students. They conclude with a key question: 'What conditions are necessary for science fair projects to contribute equally to all high school children's learning and future opportunities?'

In 'Calculus for Teachers: Perspectives and Considerations of Mathematicians', Yan, et al. (2020) explore mathematicians' perspective on a Calculus course for prospective secondary school teachers. They used the Essence-Doing-Worth (EDW) conceptual framework (Hoffmann \& Even, 2018, 2019) to study the relevance and contribution of academic mathematics courses to the teaching of secondary school mathematics. They interviewed 24 mathematicians to learn about their views on an envisioned Calculus course. They used the nine initial themes from the EDW framework to analyze the perspectives of the mathematicians. They found that the majority of the participants recognized the importance of mathematical investigations, and making connections within and beyond the subject. The mathematicians proposed that the Calculus course for secondary school teachers should feature the human dimension of mathematical activity and development. They also expanded the Worth category of the EDW conceptual framework (Hoffmann \& Even, 2018, 2019) by adding 'the worth of Calculus as a human activity'.

Gallant et al. (2020) investigated 184 female Grade 10 and 11 student's perspectives about STEM after they engaged in a two-day scientific conference. The authors wanted to know the impact of the conference on the student's confidence in attending university, their interest in pursuing STEM programs, and if the confidence and interest differ for first-generation students. The authors found that the majority of first-generation students reported that their confidence level did increase as compared with continuing-generation students. As they also found that these two-day conferences do increase the student's confidence in attending university, this outreach initiative has many benefits for first-generation students. The authors provide us with other findings that support university-based STEM initiatives. 
Mathematics achievement of Canadian elementary school students has been declining over a number of years. Wickstrom et al. (2020) identified latent profiles of elementary school students engaged in large-scale mathematics tests in Ontario, Canada, and determined the factors that predict membership in these subpopulations. They found that individual education plans and testing accommodations significantly predicted membership to a latent profile of declining mathematics achievement. The authors describe the implications for educational practice and advocate for early identification and intervention to support mathematics learning. Their findings indicate that learners with special needs require more support than they currently receive in large-scale mathematics testing in Ontario.

In CJSMTE's Volume 20 Issue 2, the Special Theme offers readers critical re-imaginings of the role of mathematics in STEM fields and STEM education, and the other part of the issue provides rich and thoughtprovoking articles to all of our readers during these challenging circumstances due to the COVID-19 health crisis. As I wrote at the beginning of this editorial, we have all been trying to protect our community and our journal's cherished team has risen to the responsibility of that challenge. I want to thank the editors and staff at this journal as well as Springer for their dedication to bringing you valuable and insightful research. I hope you find time to explore the research presented in this issue.

\section{References}

Abtahi, Y. (2020). The "M" in STEM as a note of caution: Resilient to what and responsive to whose culture. Canadian Journal of Science, Mathematics, and Technology Education, 20(2). https://doi.org/10.1007/s42330-020-00093-8.

Bowen, G.M., \& Stelmach, B. (2020). Parental helping with science fair projects: a case study. Canadian Journal of Science, Mathematics, and Technology Education, 20(2). https://doi.org/10.1007/s42330-020-00087-6.

Gallant, C., Bork, P., Carpenter-Cleland, C., \& Good, D. (2020). Examining the impact of a 2-day scientific conference on high school students' interest in STEM and confidence in attending university. Canadian Journal of Science, Mathematics, and Technology Education, 20(2). https://doi.org/10.1007/s42330-020-00086-7.

Glanfield, F., Thom, J., \& Ghostkeeper, E. (2020). Living landscapes, archi-text-ures, and land-guaging algo-rhythms. Canadian. Journal of Science, Mathematics, and Technology Education, 20(2). https://doi.org/10.1007/s42330-02000085-8

Hanin, V., \& Van Nieuwenhoven, C. (2020). An exploration of the cognitive, motivational, emotional and regulatory behaviors of elementary-school novice and expert problem solvers. Canadian Journal of Science, Mathematics, and Technology Education, 20(2). https://doi.org/10.1007/s42330-020-00092-9.

Hoffmann, A., \& Even, R. (2018). What do mathematicians wish to teach teachers in secondary school about mathematics? In E. Bergqvist, M. Österholm, C. Granberg, \& L. Sumpter (Eds.), Proceedings of the 42nd Conference of the International Group for the Psychology of Mathematics Education (Vol. 3, pp. 99-106). Umeå: PME.

Hoffmann, A., \& Even, R. (2019). Contribution of academic mathematics to teacher learning about the essence of mathematics. In the Proceedings of the $43^{\text {rd }}$ Conference of the International Group for the Psychology of Mathematics Education (Vol. 1, pp. XX-YY). Pretoria, South Africa: PME.

Khan, S. (2020). After the M in STEM: Towards mathematics for multispecies flourishing. Canadian Journal of Science, Mathematics, and Technology Education, 20(2). https://doi.org/10.1007/s42330-020-00089-4.

Marker, M., \& Hardman, S. (2020). The math people: Unwitting agents of empire who "like to stay in their lane". Canadian Journal of Science, Mathematics, and Technology Education, 20(2). https://doi.org/10.1007/s42330-020-00094-7.

Nicol, C., Gerofsky, S., Nolan, K., Francis, K., \& Fritzlan, A. (2020). Teacher educator professional learning with/in place: Storying the work of decolonizing mathematics education within a colonial structure. Canadian Journal of Science, Mathematics, and Technology Education, 20(2). https://doi.org/10.1007/s42330-020-00080-z.

Leung, F., Radzimski, V., \& Doolittle, E. (2020). Re-imagining authentic mathematical experiences for non-STEM majors. Canadian Journal of Science, Mathematics, and Technology Education, 20(2). https://doi.org/10.1007/s42330-02000084-9.

Parkin, A. (2018). Supporting Education Transformation in Canada. Retrieved from https://canada2067.ca/app/uploads/2018 /11/Canada-2067-Supporting-Education-Transformation-in-Canada_Final.pdf. Accessed 28 Apr 2020.

Wickstrom, H., Fesseha, E., \& Jang, E.E. (2020). Examining the relation between IEP status, testing accommodations, and elementary students' EQAO mathematics achievement. Canadian Journal of Science, Mathematics, and Technology Education, 20(2). https://doi.org/10.1007/s42330-020-00088-5.

Wiseman, D., Borden, L., Beatty, R., Jao, L., \& Carter, E. (2020). Whole-some artifacts: (STEM) teaching and learning emerging from and contributing to community. Canadian Journal of Science, Mathematics, and Technology Education, 20(2). https://doi.org/10.1007/s42330-020-00079-6. 
Yan, X., Marmur, O., \& Zazkis, R. (2020). Calculus for teachers: Perspectives and considerations of mathematicians. Canadian Journal of Science, Mathematics, and Technology Education, 20(2). https://doi.org/10.1007/s42330-020-00090-x.

Yaro, K., Amoah, E., \& Wagner, D. (2020). Situated perspectives on creating mathematics tasks for peace and sustainability. Canadian Journal of Science, Mathematics, and Technology Education, 20(2). https://doi.org/10.1007/s42330-02000083-w.

Publisher's Note Springer Nature remains neutral with regard to jurisdictional claims in published maps and institutional affiliations. 